\title{
Sip-jeon-dea-bo-tang, a traditional herbal medicine, ameliorates cisplatin-induced anorexia via the activation of JAK1/STAT3-mediated leptin and IL-6 production in the fat tissue of mice
}

\author{
SANG-MI WOO ${ }^{1}$, YOUN KYUNG CHOI ${ }^{1}$, AH-JEONG KIM ${ }^{1}$, YEE JIN YUN ${ }^{1}$, YONG CHEOL SHIN ${ }^{1}$, \\ SUNG-GOOK $\mathrm{CHO}^{1,2}$ and SEONG GYU KO ${ }^{1}$
}

\footnotetext{
${ }^{1}$ Department of Preventive Medicine, College of Republic of Korean Medicine, Kyung Hee University, Seoul 130-701;

${ }^{2}$ Department of Biotechnology, Korea National University of Transportation, Chungbuk 368-701, Republic of Korea
}

Received February 12, 2015; Accepted January 4, 2016

DOI: $10.3892 / \mathrm{mmr} .2016 .4889$

\begin{abstract}
Despite its therapeutic advantages, chemotherapy can also cause adverse effects, including anorexia and loss of appetite. Although numerous patients with cancer have been reported to suffer from anorexia during or following chemotherapy, treatment options for anorexia remain to be determined. In Asian countries, traditional medicines are widely used to treat problems with appetite; sip-jeon-dea-bo-tang (SJDBT) is one of those medicines used for the treatment of anorexia. The present study demonstrated that SJDBT ameliorated cisplatin-induced anorexia. In a mouse model of chemotherapy-induced anorexia, oral administration of SJDBT prevented the cisplatin-induced reduction of food intake, inhibiting weight loss. The results of multiplex assays showed that SJDBT only altered the levels of interleukin (IL)-6 and leptin in the serum and fat tissue. In addition, SJDBT maintained the serum leptin level and increased the serum IL-6 level, whereas cisplatin reduced the levels of both serum leptin and IL-6. Furthermore, SJDBT was revealed to increase the levels of leptin and IL-6 in the fat tissue by activating the JAK1/STAT3 signaling pathway. In conclusion, the present results revealed that SJDBT ameliorated cisplatin-induced anorexia, suggesting its usefulness in the prevention of anorexia during chemotherapy.
\end{abstract}

Correspondence to: Dr Seong Gyu Ko, Department of Preventive Medicine, College of Republic of Korean Medicine, Kyung Hee University, 1 Hoegi-dong, Dongdaemun-gu, Seoul 130-701, Republic of Korea

E-mail: epiko@khu.ac.kr

Key words: Sip-jeon-dea-bo-tang, anorexia, leptin, interleukin-6, JAK1/STAT3

\section{Introduction}

It has been reported that $\sim 50 \%$ of patients with cancer suffer from anorexia, one of the adverse effects caused by chemotherapy (1-3). Cancer patients with anorexia exhibit symptoms, including loss of appetite, weight loss, chronic fatigue, lethargy and anemia $(4,5)$. When these symptoms become chronic, a loss of fat and muscle is observed, which is closely associated with cachexia (6). Anorexia is a major concern for patients with cancer, since it worsens the quality of life and becomes an obstacle in cancer therapies, often resulting in poor prognosis (7-9). Although certain drugs have been suggested, the therapeutic options for the treatment of anorexia remain to be determined $(10,11)$. Leptin, a hormone secreted predominantly by fat tissue, modulates food intake and energy balance (12-14). Low levels of leptin are often observed in cancer patients with anorexia $(13,15)$, suggesting that balanced leptin levels may be crucial in the prevention of anorexia. Interleukin (IL)-6 regulates leptin production and vice versa (16-19). Furthermore, the deletion of the IL-6 receptor in mice causes a decrease in both food intake and body weight (20). It has been revealed that the Janus kinase (JAK)1/signal transducer and activator of transcription (STAT)3 pathway regulates the production of leptin and IL-6 in the fat tissue $(21,22)$.

Sip-jeon-dea-bo-tang (SJDBT), is a traditional herbal medicine, widely used in the treatment of various diseases, including anorexia, anemia, extreme fatigue and weakness, in Korea, China and Japan (23-26). SJDBT has been revealed to exhibit anticancer effects (27-29). Previously, it was revealed that SJDBT ameliorates cancer-induced anorexia and cachexia (30). In addition, SJDBT has been reported to mitigate various chemotherapy-induced side effects (31-34). Based on the aforementioned findings, SJDBT appears to have multiple roles in the treatment of cancer; however, it remains unclear how SJDBT ameliorates chemotherapy-induced anorexia. In the present study, the effect of SJDBT in cisplatin-induced anorexia in mice was investigated. SJDBT 

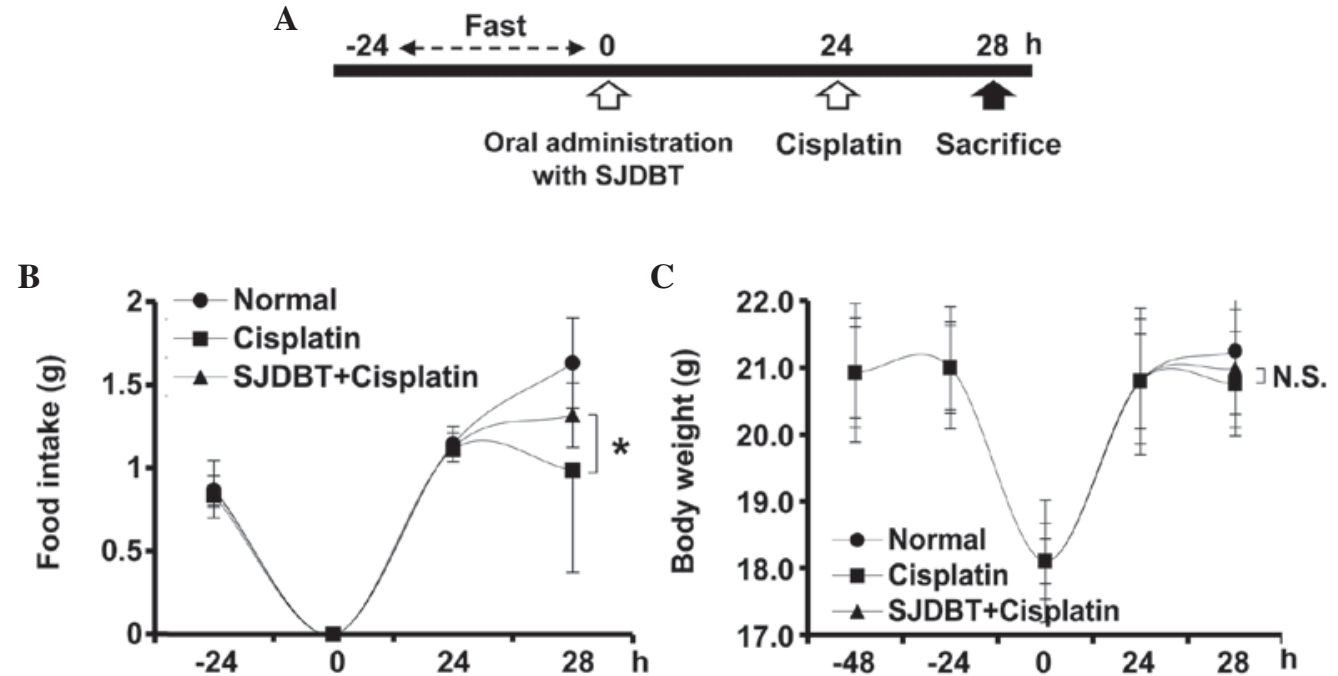

Figure 1. SJDBT prevents the cisplatin-induced decrease in food intake in mice. (A) The experimental design for accessing the effect of SJDBT on cisplatin-induced anorexia in mice. (B) Food intake and (C) body weight were measured at the indicated time points ("P<0.05). Data are presented as the mean \pm standard deviation ( $\mathrm{n}=6$ per group). SJDBT, Sip-jeon-dea-bo-tang; N.S., no statistical difference.

was revealed to ameliorate food intake and body weight by altering the levels of leptin and IL-6. In the fat tissue, SJDBT activated the JAK1/STAT3 signaling pathway, resulting in the production of both leptin and IL-6; therefore, the present data suggested that SJDBT may be useful in the prevention of chemotherapy-induced anorexia.

\section{Materials and methods}

Materials. Cisplatin was purchased from Sigma-Aldrich (St. Louis, MO, USA) and SJDBT was obtained from Hanpoong Pharm \& Foods Co., Ltd., (Jeonju, Republic of Korea). SJDBT extract was prepared, according to the Good Manufacturing Practices guidelines (35-37). Briefly, 10 of the components comprising SJDBT [Angelica gigas, Astragalus membranaceus, Atractylodes japonica, Cinnamomum cassia, Cnidium officinale, Paeonia lactiflora, Panax ginseng, Poria cocos and Rehmannia glutinosa (320 g each), and Glycyrrhiza uralensis $(160 \mathrm{~g})]$ were placed in 10 -fold volume of water, boiled at $100^{\circ} \mathrm{C}$ for $3 \mathrm{~h}$, filtered using $25 \mu \mathrm{m}$ microfilters, and were subsequently extracted at $60^{\circ} \mathrm{C}$. Finally, $876.9 \mathrm{~g}$ dried extract was obtained and the average yield was $\sim 28.85 \%$. Megestrol acetate (MA; Megace ${ }^{\circledR}$ ) was purchased from Santa Cruz Biotechnology, Inc. (Santa Cruz, CA, USA). Primary polyclonal antibodies against phosphorylated (p-)JAK1, (3331) p-STAT3 (9131), STAT3 (9132), p-AKT (9271) and AKT (9272) were purchased from Cell Signaling Technologies (Danvers, MA, USA). Anti- $\alpha$-tubulin monoclonal antibody (T-5168) was purchased from Sigma-Aldrich (St. Louis, MO, USA).

Animal study. A total of 42 male Balb/c mice (6-weeks-old) were purchased from Orient Bio Inc. (Seongnam, South Korea) and were maintained at $23 \pm 3^{\circ} \mathrm{C}$ (humidity, $55 \pm 15 \%$ ) with a $12 \mathrm{~h} \mathrm{light/dark} \mathrm{cycle.} \mathrm{Water} \mathrm{was} \mathrm{continuously} \mathrm{provided}$ during whole experimental period. Following fasting for $24 \mathrm{~h}$, mice were provided with food for $28 \mathrm{~h}$ and food intake was observed at the indicated times (Fig. 1A). Mice were randomly split into three equal groups ( $\mathrm{n}=6 /$ group) as follows: Normal, cisplatin and SJDBT + cisplatin. Water and food were provided enough, and food was changed daily. Food intake was observed daily at the consistent times (Fig 2A). Mice were randomly split into three equal groups ( $\mathrm{n}=6$ /group) as follows: Normal, cisplatin, SJDBT + cisplatin and MA + cisplatin. Briefly, $8 \mathrm{mg} / \mathrm{kg}$ cisplatin dissolved in water was intraperitoneally injected into the mice, followed by daily oral administration of $678.4 \mathrm{mg} / \mathrm{kg}$ SJDBT dissolved in water and $100 \mathrm{mg} / \mathrm{kg}$ MA dissolved in corn oil. The present animal study was approved by the Animal Ethics Committee of Kyung Hee University [KHUASP (SE)-012-048]. Upon completion of the experiment, mice were anesthetized

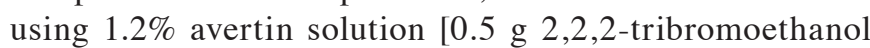
powder dissolved into $1 \mathrm{ml} \mathrm{2-methyl-2-butanol} \mathrm{at} 55^{\circ} \mathrm{C}$ and $39 \mathrm{ml}$ phosphate-buffered saline (PBS)] through a Nalgene $0.22-\mu$ filter (Thermo Fisher Scientific, Inc., Waltham, MA, USA) (1) and sacrificed via exsanguination.

Enzyme-linked immunosorbent assay (ELISA). In order to obtain the serum, blood was centrifuged at $22.4 \mathrm{x}$ g for $20 \mathrm{~min}$ at room temperature and the supernatant was transferred to a new tube. Upon completion of the experiment, the levels of IL-6 and leptin in the serum were measured using the Millipore Mouse Metabolic Magnetic Bead Panel kit (EMD Millipore, Billerica, MA, USA), according to the manufacturer's protocol. Next, the levels of mouse IL-6 (BD 555240; BD Biosciences, San Jose, CA, USA) and mouse leptin (DY498; R\&D Systems, Inc., Minneapolis, MN, USA) were measured using ELISA kits according to the manufacturer's protocol. All experiments were performed in triplicate.

Western blot analysis. Primary fat tissues were isolated from the mice and were lysed using radioimmunoprecipitation buffer (Biosesang, Scongnam, Korea) to obtain whole protein. Protein concentration was measured using the Bradford assay and $10 \mu \mathrm{g}$ protein was separated by $8 \%$ sodium dodecyl sulfate-polyacrylamide gels electrophoresis. 
A

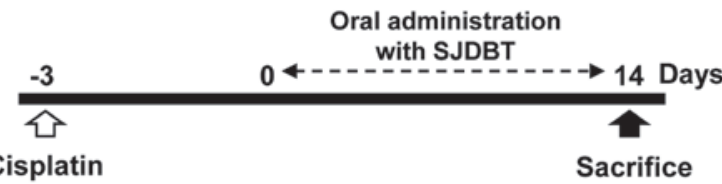

B

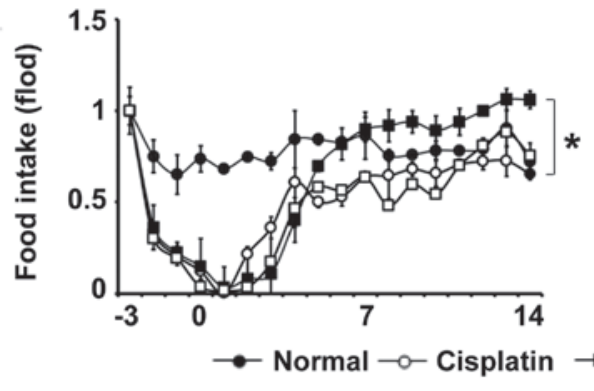

D

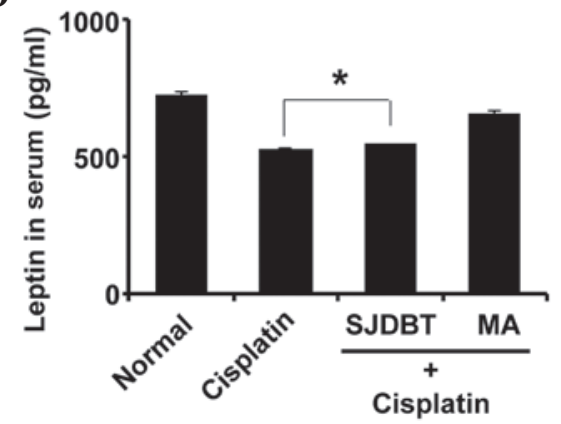

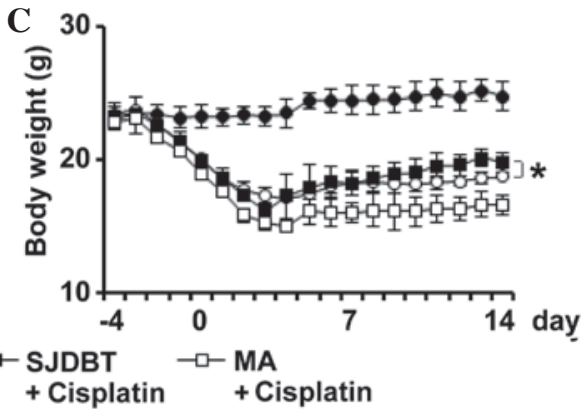

$\mathbf{E}$

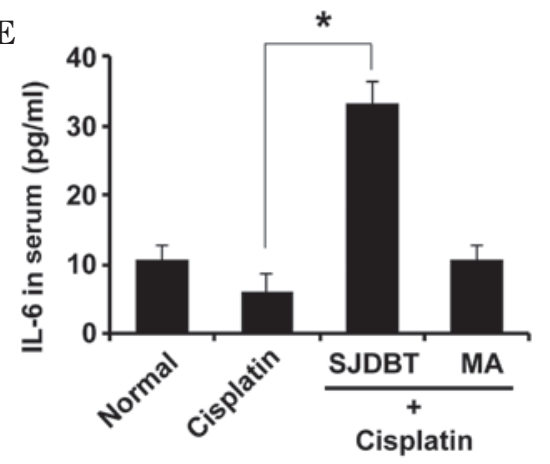

Figure 2. Long-term administration of SJDBT prevents cisplatin-induced anorexia in mice. (A) The experimental design used to investigate the effect of SJDBT on cisplatin-induced anorexia. Measurements of (B) food intake, (C) body weight and the levels of (D) leptin and (E) IL-6 in the serum of mice were obtained ( $\mathrm{P}<0.05$ ). Data are presented as the mean \pm standard deviation ( $\mathrm{n}=6$ per group). SJDBT, Sip-jeon-dea-bo-tang; IL, interleukin; MA, megestrol acetate.

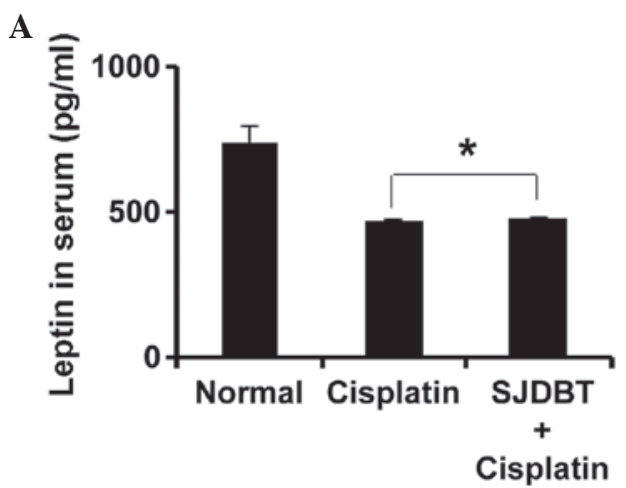

C

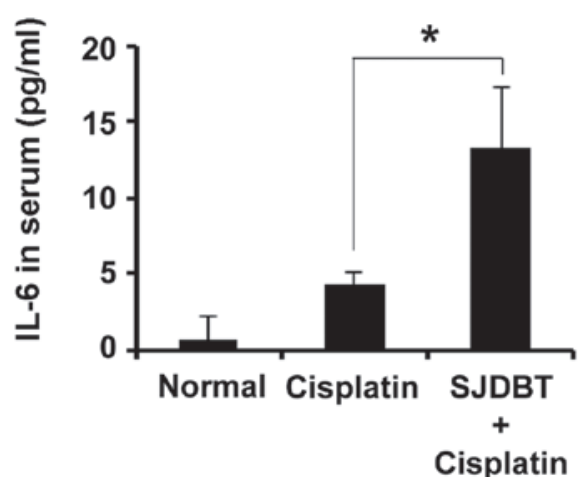

B

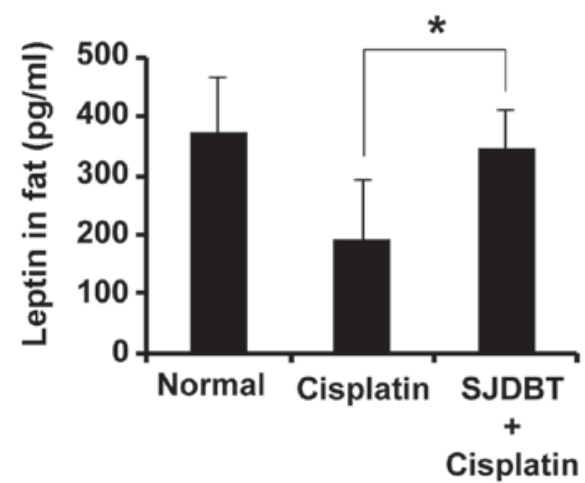

D

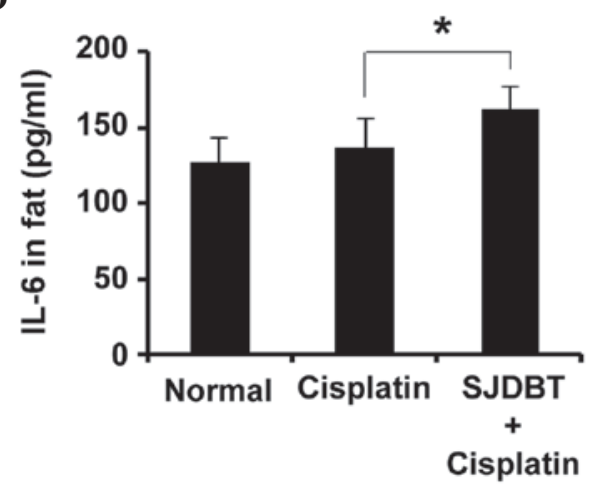

Figure 3. SJDBT increases the levels of leptin and IL-6 in the serum and fat of mice. An enzyme-linked immunosorbent assay was used to measure the leptin levels in the (A) serum and (B) fat tissue of mice and IL-6 levels in the (C) serum and (D) fat tissue of mice ( $\left.{ }^{*}<<0.05\right)$. Data are presented as the mean \pm standard deviation (n=6 per group). SJDBT, Sip-jeon-dea-bo-tang; IL, interleukin. 

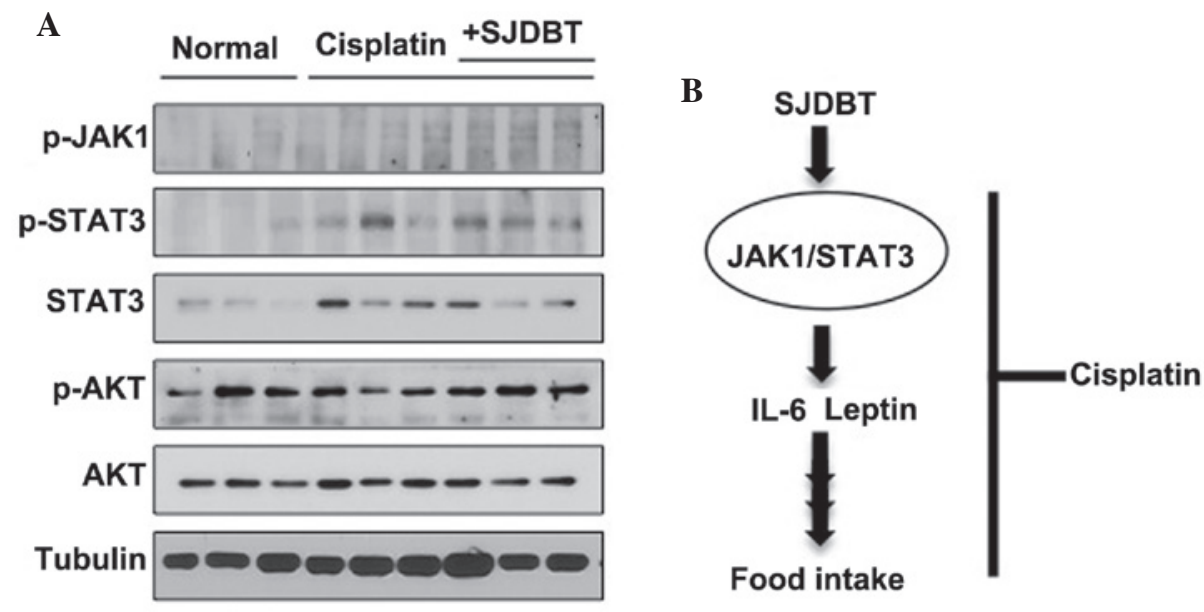

Figure 4. SJDBT activates JAK1 and STAT3 in the fat tissue of mice. (A) Western blot analysis of protein samples from the fat tissues of three different mice in the same groups were loaded. Tubulin was used as a loading control. (B) A schematic model summarizing the effect of SJDBT on cisplatin-induced anorexia. SJDBT promotes the production of IL-6 and leptin by activating the JAK1/STAT3-mediated signaling pathway in the fat of mice, resulting in the prevention of cisplatin-induced anorexia. SJDBT, Sip-jeon-dea-bo-tang; IL, interleukin; p-, phosphorylated; JAK, Janus kinase; STAT, signal transducer and activator of transcription; AKT, protein kinase B.

Separated proteins were transferred onto polyvinylidene difluoride membranes (both GE Healthcare Life Sciences, Freiburg, Germany) and the membranes were subsequently blocked in $1 \%$ bovine serum albumin (BSA) and $2 \%$ skimmed milk for $1 \mathrm{~h}$. Following incubation at $4^{\circ} \mathrm{C}$ overnight with the following primary polyclonal antibodies against: p-JAK1, p-STAT3, STAT3, p-AKT, AKT (all 1:1,000) and monoclonal anti- $\alpha$-tubulin (1:100,000 in 3\% BSA), the membranes were incubated at room temperature for $1 \mathrm{~h}$ with horseradish peroxidase-conjugated goat anti-rabbit immunglobulin $\mathrm{G}$ (H+L) secondary antibody (KPL, Inc., Gaithersburg, MA, USA). The membranes were washed three times in PBS with $0.01 \%$ Tween-20 between each step. In order to visualize the membranes, enhanced chemiluminescence (ECL) kit solution (DoGen, Seoul, Korea) was used and the membranes were exposed to X-ray film (AGFA Healthcare, Mortsel, Belgium).

Statistical analysis. Statistical differences were calculated via Student's t-test using Microsoft Excel 2007 (Microsoft Corporation, Redmond, WA, USA). Data were presented as the mean \pm standard deviation. $\mathrm{P}<0.05$ was considered to indicate a statistically significant difference.

\section{Results}

SJDBT prevents a cisplatin-mediated decrease in food intake. The effect of SJDBT on the food intake of mice treated with cisplatin was investigated. The mice were initially subjected to an oral administration of SJDBT or water, and subsequently to an intraperitoneal injection of cisplatin (Fig. 1A). By contrast to the cisplatin-treated mice previously described $(34,38)$, in which a decrease in food intake was observed, the mice treated with SJDBT + cisplatin did not exhibit the same cisplatin-induced decrease (Fig. 1B). In addition, no body weight loss was observed in any of the mice in this experiment (Fig. 1C); therefore, the present data indicated that SJDBT prevented a cisplatin-induced decrease in food intake in mice.
Long-term treatment of SJDBT ameliorates cisplatin-induced anorexia. The present study next examined whether long-term treatment with SJDBT is effective in cisplatin-induced anorexic mice. Three days following cisplatin treatment, the mice received oral administration of water, SJDBT or MA, every day for 14 days. Food and water were changed daily, and the food intake and body weight were measured daily (Fig. 2A). Food intake and body weight were markedly reduced 3 days following cisplatin treatment (Fig. 2B and C), confirming the success of the mouse model of chemotherapy-induced anorexia. SJDBT was shown to markedly restore the cisplatin-induced decrease in food intake, and recover the body weight of the mice (Fig. 2B and C). Subsequently, the serum levels of leptin and IL-6, which are considered markers for anorexia, were measured. It was revealed that cisplatin reduced the levels of serum leptin and IL-6, consistent with previous studies $(39,40)$, whereas SJDBT was shown to restore them (Fig. 2D), suggesting that long-term treatment with SJDBT may prove useful in the treatment of cisplatin-induced anorexia.

SJDBT increases the levels of leptin and IL-6. Since leptin and IL-6 are considered as markers for anorexia, their serum and fat levels were measured in the mice from the previous experiment. Cisplatin was revealed to reduce the serum level of leptin, whereas SJDBT was shown to slightly increase the levels of leptin (Fig. 3A). Furthermore, SJDBT significantly rescued the cisplatin-mediated reduction in the level of leptin in the fat (Fig. 3B). Similarly, SJDBT increased the IL-6 levels in the serum (Fig. 3C) and fat tissues (Fig. 3D); therefore, the present data suggested that SJDBT may ameliorate cisplatin-induced anorexia via the regulation of the leptin and IL-6 levels in the fat tissue.

SJDBT increases the levels of leptin and IL- 6 via the activation the JAK/STAT3 signaling pathway in the fat tissues of mice. The JAK1/2-STAT3 signaling pathway has been shown to regulate both IL-6 and leptin production $(16,17)$. Fat tissues 
were isolated and were subsequently used for western blotting. This revealed that SJDBT regulated the phosphorylation of both JAK1 and STAT3, but not AKT (Fig. 4A). The present data therefore suggested that the SJDBT-mediated treatment of anorexia occurs as a result of the JAK1/STAT3-mediated production of leptin and IL-6 in the fat of mice.

\section{Discussion}

SJDBT has been reported to ameliorate chemotherapy-mediated side effects in mice and cancer patients $(26,31,33,41)$; however, its protective role against chemotherapy-induced anorexia remains to be elucidated. In the present study, it was found that SJDBT prevented the cisplatin-induced decrease in food intake and body weights in mice via the regulation of the JAK1/STAT3-mediated production of leptin and IL-6 in the fat tissue of mice $(21,22)$.

Our previous study revealed that SJDBT regulated various cytokines and hormones involved in appetite, including IL-6, monocyte chemoattractant protein-1, peptide YY and glucagon-like peptide-1, and ameliorated cancer-induced anemia (30). In addition, SJDBT has been shown to protect immune defects in patients with cancer undergoing chemotherapy $(31-33,41)$. The regulation of cytokine production by SJDBT appears to have unique therapeutic effects; however, its role against anorexia remains to be elucidated. In the present study, it was found that SJDBT restored decreased food intake levels and the decreased body weight induced by cisplatin. Furthermore, SJDBT regulated the production of IL- 6 and leptin.

In our previous study, SJDBT failed to regulate the level of leptin in tumor-bearing mice (30), which suggests that the regulation of leptin by SJDBT appears to be limited to cisplatin-induced anorexia. In addition, the data from multiplex assays revealed that SJDBT did not markedly alter various cytokines and hormones, including ghrelin, in both cisplatin-induced and cancer-associated anorexia mouse models (data not shown). Therefore, SJDBT regulation of IL-6 production seems to be unique in experimental systems reflecting either chemotherapy-induced or cancer-associated anorexia. IL-6 is known to regulate anorexia and cachexia, which is crucial for the improvement of the survival rates of patients with cancer (42). IL-6 is also known to activates the JAK/STAT signaling pathway, resulting in an increase in IL-6 production $(43,44)$. In the present study, SJDBT activated JAK1 and STAT3, but not AKT, suggesting that SJDBT regulates food intake by activating JAK1/STAT3-mediated IL-6 production.

It remains unknown which compounds in SJDBT are effective and what their effects are in cells, tissues and organs, which comprises a major challenge for studies on herbal medicines. With regard to SJDBT, high performance liquid chromatography fingerprint analysis was performed (45), thereby providing hints for effective components.

Numerous patients from countries in East Asia receive SJDBT for the treatment of certain diseases, including various cancers, anorexia, cachexia, chronic fatigue, immunization disease, female disorder and blood-flow disorders, despite the lack of scientific evidence regarding the role of SJDBT in these diseases. The aim of the present study was therefore to obtain a deeper understanding of the role of SJDBT against cisplatin-induced anorexia in mice. The collected data suggested that SJDBT may be useful in the treatment of anorexia in patients with cancer undergoing chemotherapy.

It was demonstrated that SJDBT prevents cisplatin-induced anorexia in mice by regulating the JAK1/STAT3-mediated production of IL-6 and leptin, therefore suggesting that SJDBT ameliorates chemotherapy-induced anorexia.

\section{Acknowledgements}

The present study was supported by a grant from the Korean Medicine R\&D project of the Ministry of Health and Welfare (no. B120014) and by the National Research Foundation of Korea, which is funded by the Ministry of Science (grant no. 2007-0054931).

\section{References}

1. Inui A: Cancer anorexia-cachexia syndrome: Current issues in research and management. CA Cancer J Clin 52: 72-91, 2002.

2. Sinno MH, Coquerel Q, Boukhettala N, Coëffier M, Gallas S, Terashi M, Ibrahim A, Breuillé D, Déchelotte $\mathrm{P}$ and Fetissov SO: Chemotherapy-induced anorexia is accompanied by activation of brain pathways signaling dehydration. Physiol Behav 101: 639-648, 2010.

3. Jahn P, Renz P, Stukenkemper J, Book K, Kuss O, Jordan K, Horn I, Thoke-Colberg A, Schmoll HJ and Landenberger M: Reduction of chemotherapy-induced anorexia, nausea and emesis through a structured nursing intervention: A cluster-randomized multicenter trial. Support Care Cancer 17: 1543-1552, 2009.

4. Abell TL, Malagelada JR, Lucas AR, Brown ML, Camilleri M, Go VL, Azpiroz F, Callaway CW, Kao PC, Zinsmeister AR, et al: Gastric electromechanical and neurohormonal function in anorexia nervosa. Gastroenterology 93: 958-965, 1987

5. Bernstein IL and Bernstein ID: Learned food aversions and cancer anorexia. Cancer Treat Rep 65 (Suppl 5): S43-S47, 1981.

6. Mantovani G, Macció A, Massa E and Madeddu C: Managing cancer-related anorexia/cachexia. Drugs 61: 499-514, 2001

7. Langhans W: Anorexia of infection: Current prospects. Nutrition 16: 996-1005, 2000.

8. Exton MS: Infection-induced anorexia: Active host defence strategy. Appetite 29: 369-383, 1997.

9. Tohgo A, Kumazawa E, Akahane K, Asakawa A and Inui A: Anticancer drugs that induce cancer-associated cachectic syndromes. Expert Rev Anticancer Ther 2: 121-129, 2002.

10. Suárez-Pinilla P, Peña-Pérez C, Arbaizar-Barrenechea B, Crespo-Facorro B, Del Barrio JA, Treasure J and Llorca-Díaz J: Inpatient treatment for anorexia nervosa: A systematic review of randomized controlled trials. J Psychiatr Pract 21: 49-59, 2015.

11. Mondello P, Mian M, Aloisi C, Famá F, Mondello S and Pitini V: Cancer cachexia syndrome: Pathogenesis, diagnosis and new therapeutic options. Nutr Cancer 67: 12-26, 2015.

12. Brennan AM and Mantzoros CS: Drug Insight: The role of leptin in human physiology and pathophysiology-emerging clinical applications. Nat Clin Pract Endocrinol Metab 2: 318-327, 2006.

13. Hebebrand J, Muller TD, Holtkamp $\mathrm{K}$ and Herpertz-Dahlmann B: The role of leptin in anorexia nervosa: Clinical implications. Mol Psychiatry 12: 23-35, 2007.

14. Eckert ED, Pomeroy C, Raymond N, Kohler PF, Thuras P and Bowers CY: Leptin in anorexia nervosa. J Clin Endocrinol Metab 83: 791-795, 1998

15. Smiechowska J, Utech A, Taffet G, Hayes T, Marcelli M and Garcia JM: Adipokines in patients with cancer anorexia and cachexia. J Investig Med 58: 554-559, 2010.

16. Tang CH, Lu DY, Yang RS, Tsai HY, Kao MC, Fu WM and Chen YF: Leptin-induced IL-6 production is mediated by leptin receptor, insulin receptor substrate-1, phosphatidylinositol 3-kinase, Akt, NF-kappaB and p300 pathway in microglia. J Immunol 179: 1292-1302, 2007. 
17. Trujillo ME, Sullivan S, Harten I, Schneider SH, Greenberg AS and Fried SK: Interleukin-6 regulates human adipose tissue lipid metabolism and leptin production in vitro. J Clin Endocrinol Metab 89: 5577-5582, 2004.

18. Engineer DR and Garcia JM: Leptin in anorexia and cachexia syndrome. Int J Pept 2012: 287457, 2012.

19. Faggioni R, Feingold KR and Grunfeld C: Leptin regulation of the immune response and the immunodeficiency of malnutrition. FASEB J 15: 2565-2571, 2001

20. Shirazi R, Palsdottir V, Collander J, Anesten F, Vogel H, Langlet F, Jaschke A, Schürmann A, Prévot V, Shao R, et al: Glucagon-like peptide 1 receptor induced suppression of food intake and body weight is mediated by central IL-1 and IL-6. Proc Natl Acad Sci USA 110: 16199-16204, 2013.

21. Hübschle T, Thom E, Watson A, Roth J, Klaus S and Meyerhof W: Leptin-induced nuclear translocation of STAT3 immunoreactivity in hypothalamic nuclei involved in body weight regulation. J Neurosci 21: 2413-2424, 2001.

22. Priceman SJ, Kujawski M, Shen S, Cherryholmes GA, Lee H, Zhang C, Kruper L, Mortimer J, Jove R, Riggs AD and Yu H: Regulation of adipose tissue $\mathrm{T}$ cell subsets by Stat 3 is crucial for diet-induced obesity and insulin resistance. Proc Natl Acad Sci USA 110: 13079-13084, 2013.

23. Borman NH: The history of ancient Korean medicine. Yonsei Med J 7: 103-118, 1966.

24. Zee-Cheng RK: Shi-quan-da-bu-tang (ten significant tonic decoction), SQT. A potent Chinese biological response modifier in cancer immunotherapy, potentiation and detoxification of anticancer drugs. Methods Find Exp Clin Pharmacol 14: 725-736, 1992.

25. Saiki I: A Kampo medicine 'Juzen-taiho-to' prevention of malignant progression and metastasis of tumor cells and the mechanism of action. Biol Pharm Bull 23: 677-688, 2000.

26. Kishida Y, Nishii T, Inoue T, Nishida S, Arimitsu J, Yoshikawa H and Sugano N: Juzentaihoto (TJ-48), a traditional Japanese herbal medicine, influences hemoglobin recovery during preoperative autologous blood donation and after hip surgery. Int J Clin Pharmacol Ther 47: 716-721, 2009.

27. Wang CY, Bai XY and Wang CH: Traditional Chinese medicine: A treasured natural resource of anticancer drug research and development. Am J Chin Med 42: 543-559, 2014

28. Kin R, Kato S, Kaneto N, Sakurai H, Hayakawa Y, Li F, Tanaka K, Saiki I and Yokoyama S: Procyanidin C1 from cinnamomi cortex inhibits TGF- $\beta$-induced epithelial-to-mesenchymal transition in the A549 lung cancer cell line. Int J Oncol 43: 1901-1906, 2013

29. Matsuda T, Maekawa K, Asano K and Hisamitsu T: Suppressive effect of juzen-taiho-to on lung metastasis of b16 melanoma cells in vivo. Evid Based Complement Alternat Med 2011: 743153, 2011.

30. Choi YK, Jung KY, Woo SM, Yun YJ, Jun CY, Park JH, Shin YC, Cho SG and Ko SG: Effect of Sipjeondaebo-tang on cancer-induced anorexia and cachexia in CT-26 tumor-bearing mice. Mediators Inflamm 2014: 736563, 2014

31. Huang SM, Chien LY, Tai CJ, Chiou JF, Chen CS and Tai CJ Effectiveness of 3-week intervention of Shi Quan Da Bu Tang for alleviating hematotoxicity among patients with breast carcinoma receiving chemotherapy. Integr Cancer Ther 12: 136-144, 2013.
32. Ogawa K, Omatsu T, Matsumoto C, Tsuchiya N, Yamamoto M, Naito Y and Yoshikawa T: Protective effect of the Japanese traditional medicine juzentaihoto on myelosuppression induced by the anticancer drug TS- 1 and identification of a potential biomarker of this effect. BMC Complement Altern Med 12: 118, 2012.

33. Sugiyama K, Ueda $\mathrm{H}$ and Ichio Y: Protective effect of juzen-taiho-to against carboplatin-induced toxic side effects in mice. Biol Pharm Bull 18: 544-548, 1995.

34. Talley RW, O'Bryan RM, Gutterman JU, Brownlee RW and McCredie KB: Clinical evaluation of toxic effects of cis-diamminedichloroplatinum (NSC-119875)-phase I clinical study. Cancer Chemother Rep 57: 465-471, 1973.

35. Safety MOFAD: Guidance on good manufacturing practices (GMP) for active pharmaceutical ingredients. 2nd Edition. Korea 2015.

36. World Health Organization: Annex 3 supplementary guidelines on good manufacturing practices for the manufacture of herbal medicines. WHO Technical Report Series, pp85-106, 2006.

37. Center for Drug Evaluation and Research PQMSC: Pharmaceutical components at risk for melamine contamination services. US Dohah (ed.) 1992.

38. Higby DJ, Wallace HJ Jr and Holland JF: Cis-diamminedichloroplatinum (NSC-119875): A phase I study. Cancer Chemother Rep 57: 459-463, 1973.

39. Poth KJ, Guminski AD, Thomas GP, Leo PJ, Jabbar IA and Saunders NA: Cisplatin treatment induces a transient increase in tumorigenic potential associated with high interleukin-6 expression in head and neck squamous cell carcinoma. Mol Cancer Ther 9: 2430-2439, 2010.

40. Fantuzzi $\mathrm{G}$ and Faggioni R: Leptin in the regulation of immunity, inflammation and hematopoiesis. J Leukoc Biol 68: 437-446, 2000.

41. Sugiyama K, Ueda H, Ichio Y and Yokota M: Improvement of cisplatin toxicity and lethality by juzen-taiho-to in mice. Biol Pharm Bull 18: 53-58, 1995.

42. Suh SY, Choi YS, Yeom CH, Kwak SM, Yoon HM, Kim DG, Koh SJ, Park J, Lee MA, Lee YJ, et al: Interleukin-6 but not tumour necrosis factor-alpha predicts survival in patients with advanced cancer. Supportive Care Cancer 21: 3071-3077, 2013.

43. Wang SW and Sun YM: The IL-6/JAK/STAT3 pathway: Potential therapeutic strategies in treating colorectal cancer (Review). Int J Oncol 44: 1032-1040, 2014.

44. Huang WL, Yeh HH, Lin CC, Lai WW, Chang JY, Chang WT and Su WC: Signal transducer and activator of transcription 3 activation up-regulates interleukin-6 autocrine production: A biochemical and genetic study of established cancer cell lines and clinical isolated human cancer cells. Mol Cancer 9: 309, 2010.

45. Saiki I, Yamaura T, Ohnishi Y, Hayakawa Y, Komatsu Y and Nunome S: HPLC analysis of juzen-taiho-to and its variant formulations and their antimetastatic efficacies. Chem Pharm Bull (Tokyo) 47: 1170-1174, 1999. 